\title{
Frozen Section Diagnosis: Accuracy and Errors; with Emphasis on Reasons for Discordance
}

\author{
Roopam Kishore Gidwani ${ }^{1}$, Falguni Jay Goswami ${ }^{1 *}$, Arpan Mehta ${ }^{3}$, Nirali V Shah ${ }^{1}$ \\ Shobhana Prajapati ${ }^{1}$ and Manisha M Shah ${ }^{1}$ \\ ${ }^{1}$ Pathology Department, Medical College Vadodara, India \\ ${ }^{2}$ Neuberg Supratech ReferenceLaboratory, Ahmedabad, India
}

\section{ABSTRACT}

Background: Frozen section is a multistep process involving surgical resection, intraoperative preparation of slides and their microscopic examination. It is important to assess concordant, discordant and deferred diagnosis rates from intra-operative frozen section diagnosis with final diagnosis on paraffin section and to determine the reasons for discordance. An integral part of quality assurance in surgical pathology entails the correlation of intra-operative frozen section diagnosis with final diagnosis on permanent section.

Methods: A retrospective analysis of 117 cases of frozen section biopsy was carried out which were reported in the Histopathology department between July 2007 to June 2012. The correlation between the frozen section diagnosis with final histological diagnosis was performed in order to check the accuracy of the technique. The number and type of discrepancies were compared, causes for the discrepancies were analyzed in order to decrease the avoidable errors and improve on the frozen section diagnoses.

Results: The overall accuracy of frozen section diagnoses over 5years was $90.60 \%$ with false positive rate of $0.85 \%$, false negative rate of $6.84 \%$ and $1.71 \%$ of deferred diagnosis. Sensitivity was $87.69 \%$ and Specificity was $98 \%$. The discrepancies were mainly due to the interpretation error, sampling error and technical artefacts.

Conclusions: Gross inspection, sampling by pathologist, frozen section complemented with cytological and histological review and cooperation between consultants can avoid certain limitations and provide rapid, reliable, cost effective information necessary for optimum patient care.

Keywords: Intra-Operative Consultation, Frozen Section, Concordance, Discordance

\section{Introduction}

Intraoperative diagnostic consultation or "frozen section" (FS) is an integral part of surgical pathology. The main purpose of consultation is to help the surgeon make a therapeutic decision during the operation. ${ }^{[1,2]}$ Frozen section (FS) technique was first introduced by the eminent pathologist, William H. Welch, from Johns Hopkins Hospital in 1891. By the early and mid-1920s, the technique became popular and was used for intraoperative consultation in everyday practice. However, the technical quality of most frozen sections during these early years was suboptimal. The preparation of frozen section was made easier in the 1950s and 1960s by the development of the modern cryostat, a cabinet cooled to -20 to $-30{ }^{\circ} \mathrm{C}$ and enclosing a microtome blade. ${ }^{[3]}$

Intra-operative consultation by frozen section is a highrisk procedure with important consequences. Therefore, it is critical to determine efficiency of frozen section performance periodically. The indications of frozen section are identification of tissue and unknown pathological processes, evaluation of margins, identification of lymph node metastasis, confirmation of presence of representative samples for paraffin section diagnosis and to determine the nature of a lesion that may require ancillary test. Frozen section is chiefly performed to determine whether the tissue being sampled is malignant or benign. It should not be used to merely satisfy a surgeon's curiosity, to compensate for inadequate preoperative evaluation, or a mechanism to communicate information more quickly to the patient or patient's family. ${ }^{[4]}$

Periodic review of the correlation between frozen section diagnosis and final diagnosis is useful to identify the potential causes of errors and thus measures can be implemented to help prevent similar occurrences. Long term monitoring of frozen-permanent section correlation is associated with sustained improvement in performance. ${ }^{[5]}$

The accuracy of frozen section diagnosis can be documented by comparing the diagnosis made on the frozen sections to the final diagnosis made on the pathology specimen after review of both the frozen and permanent sections. Given the limited amount of tissue that can be submitted or sampled during frozen section examination and given the technical quality of frozen sections compared with 
permanent sections, discrepancies can be expected between frozen section diagnoses and final diagnoses. The literature reports discordance rates between frozen section diagnoses and final diagnoses ranging from $1.4 \%$ to $12.9 \%$; about $75 \%$ of studies report a discordance rate below $5 \%$, with an overall median of $2.9 \% .{ }^{[6]}$

\section{Definitions}

Concordance. An adequate frozen section study with an intraoperative diagnosis that has complete agreement with permanent section. The concordant diagnostic frequency was calculated as the total number of concordant diagnoses divided by the total number of concordant and discordant diagnoses. ${ }^{[1]}$

Deferred Diagnosis. Diagnoses that are indeterminable at the time of frozen section examination. This type of diagnosis was not considered discordant. A deferred diagnosis may involve 1 or more specimens of a given case. The frozen section evaluation of the specimen may result in 1 or more deferred frozen section diagnoses. The deferred diagnostic frequency was calculated as the total number of deferred diagnoses divided by the total number of concordant, discordant, and deferred diagnoses. ${ }^{[1]}$

Discordance. An adequate frozen section study with an intraoperative diagnosis that has diagnostic disagreement with the permanent section. Discordant frozen section diagnoses may involve 1 or more specimens of a given case. Frozen section evaluation of a specimen may result in 1 or more discordant frozen section diagnoses; a discordant diagnosis may involve 1 or more frozen section blocks.
The discordant diagnostic frequency was calculated as the total number of discordant diagnoses divided by the total number of concordant and discordant diagnoses. ${ }^{[1]}$

\section{Materials and Methods}

A retrospective comparative study of Frozen section diagnoses with routine paraffin section of 117 cases was carried out in the Histopathology department of a tertiary care center between July 2007 to June 2012. The data was retrieved from the histopathology section. Frozen sections were cut on a LEICA cryostat machine (CM1850) and evaluated in Hematoxylin and Eosin (H\&E) stain. Subsequently, for the permanent paraffin section, counterparts of frozen section specimens were fixed in 10\% formalin, grossed and adequate representative sections were taken. The paraffin sections were then evaluated in H\&E stain. The frozen section diagnoses were correlated with the final histological diagnosis to assess the accuracy of the technique. The number and type of discordant cases were compared; the cause for deferred diagnosis and the discordance were analyzed.

\section{Results}

The overall accuracy over 5 years was $90.6 \%$ with false positive rate of $00.85 \%$, false negative rate of $6.84 \%$ and $1.71 \%$ of deferred diagnosis. Sensitivity was $87.69 \%$ and Specificity was $98 \%$. The causes for false positive diagnosis were due to interpretation error and the unavoidable freezing artifact. Sampling error was the main reason for the false negative diagnosis. In 2 cases $(1.71 \%)$, diagnosis was deferred to permanent section; mainly due to lack of adequate clinical information and inadequate material.

Table 1: Frozen section diagnoses in 117 cases.

\begin{tabular}{|l|l|l|}
\hline & Number of cases & Percentage \\
\hline Accuracy & 106 & $90.6 \%$ \\
\hline False positive & 01 & $00.85 \%$ \\
\hline False negative & 08 & $6.84 \%$ \\
\hline Deferred & 02 & $1.71 \%$ \\
\hline Total & 117 & $\mathbf{1 0 0} \%$ \\
\hline
\end{tabular}

Out of 117 cases, 57(48.72\%) cases turned out to be malignant on final paraffin diagnosis. The common sites sent for frozen section are tabulated in table 2

Table 2: Organs submitted for frozen sections and the distribution of malignancies diagnosed in paraffin section.

\begin{tabular}{|l|l|l|}
\hline Organ submitted & No of cases & No of malignancies \\
\hline Breast & 29 & 16 \\
\hline Nervous system (Brain)(CNS) & 2 & 0 \\
\hline GIT (Colon) & 14 & 6 \\
\hline Thyroid Gland \& Parathyroid gland & 6 & 0 \\
\hline Ovary \& FT & 24 & 9 \\
\hline
\end{tabular}




\begin{tabular}{|l|l|l|}
\hline Organ submitted & No of cases & No of malignancies \\
\hline UB \& Male genital tract & 5 & 5 \\
\hline Pancreas & 1 & 0 \\
\hline ENT & 11 & 8 \\
\hline Hepatobiliary & 2 & 2 \\
\hline Skin & 3 & 3 \\
\hline Lymph node & 8 & 3 \\
\hline Uterus and Cervix & 7 & 3 \\
\hline Bone & 1 & 0 \\
\hline Salivary gland & 2 & 1 \\
\hline Soft Tissue & 2 & 1 \\
\hline Total & $\mathbf{1 1 7}$ & $\mathbf{5 7}$ \\
\hline
\end{tabular}

Table 3: Organ wise accuracy of frozen section.

\begin{tabular}{|c|c|c|c|c|c|c|c|}
\hline Organ & $\begin{array}{l}\text { No of } \\
\text { cases }\end{array}$ & concordant & discordant & deferral & \begin{tabular}{|l} 
False \\
positives
\end{tabular} & $\begin{array}{l}\text { False } \\
\text { negatives }\end{array}$ & $\begin{array}{l}\text { Accuracy } \\
(\%)\end{array}$ \\
\hline Breast & 29 & 26 & 3 & & 1 & 2 & 89.66 \\
\hline Nervous system & 2 & 2 & & & 0 & 0 & 100 \\
\hline GIT & 14 & 13 & 1 & & 0 & 1 & 92.86 \\
\hline Thyroid Gland \& Parathyroid gland & 6 & 6 & & & 0 & 0 & 100 \\
\hline Ovary \& FT & 24 & 20 & 3 & 1 & 0 & 3 & 87.50 \\
\hline UB \& Male genital tract & 5 & 5 & & & 0 & 0 & 100 \\
\hline Pancreas & 1 & 1 & & & 0 & 0 & 100 \\
\hline ENT & 11 & 10 & 1 & & 0 & 1 & 90.91 \\
\hline Hepatobiliary & 2 & 2 & & & 0 & 0 & 100 \\
\hline Skin & 3 & 3 & & & 0 & 0 & 100 \\
\hline Lymph node & 8 & 8 & & & 0 & 0 & 100 \\
\hline Uterus and Cervix & 7 & 7 & & & 0 & 0 & 100 \\
\hline Bone & 1 & 1 & & & 0 & 0 & 100 \\
\hline Salivary gland & 2 & 1 & 1 & 1 & 0 & 1 & 50.00 \\
\hline Soft Tissue & 2 & 2 & & & 0 & 0 & 100 \\
\hline Total & 117 & 106 & 9 & 2 & 1 & 8 & $90.6 \%$ \\
\hline
\end{tabular}

Table 4: False positive cases.

\begin{tabular}{|l|l|l|}
\hline Site & Frozen diagnosis & Final Paraffin Diagnosis \\
\hline Breast & IDC & Mammary Duct Ectasia \\
\hline
\end{tabular}

Table 5: False Negative cases.

\begin{tabular}{|l|l|l|}
\hline Site & Frozen Diagnosis & Final Paraffin Diagnosis \\
\hline Breast & Inflammatory lesion & IDC \\
\hline Breast & Lobular hyperplasia with atypical cells & IDC \\
\hline Ileocecal mass margin & Inflammatory lesion & NHL \\
\hline Ovary & Borderline Papillary serous neoplasm & Serous papillary cystadenocarcinoma \\
\hline Ovary & Borderline Epithelial tumor & Mucinous Cystadenocarcinoma \\
\hline Ovary & Papillary serous cystadenoma & Serous micro papillary carcinoma \\
\hline Nasal mass & Inflammatory lesion & NHL \\
\hline Submandibular gland & Benign salivary gland neoplasm & Acinic cell carcinoma \\
\hline
\end{tabular}


Table 6: Deferred Diagnosis.

\begin{tabular}{|l|l|l|}
\hline Site & Frozen Diagnosis & Final Paraffin Diagnosis \\
\hline Ovary and FT & $\begin{array}{l}\text { Cyst: Benign ovarian cyst } \\
\text { Nodule: Anisonucleosis, hyperchromatic nuclei }\end{array}$ & Clear cell carcinoma of ovary \\
\hline Submandibular gland & $\begin{array}{l}\text { ? Inflammatory } \\
\text { ? Malignant } \\
\text { Wait for paraffin section report }\end{array}$ & Nonspecific sialadenitis \\
\hline
\end{tabular}

\section{Discussion}

In the present study, we reviewed the frozen sections performed in Histopathology Department of Tertiary care Hospital, in a 5-year period to evaluate the diagnostic accuracy of the test in this institution. We also reviewed the discordant cases to find the reasons for discrepancy. Total number of concordant cases were106 (92.31\%) and discordant cases were divided in to one False positive $(0.85 \%)$ and 8 False negative $(6.84 \%)$ respectively. The accuracy of frozen section varies in different studies. The literature reports discordance rates ranging from $1.4 \%$ to $12.9 \%$ in different anatomical sites ${ }^{[6-8]}$

Deferred rate is also a valid parameter of quality assurance. Our study showed $2(1.71 \%)$ deferral cases which is comparable to previously published studies with a deferred rate ranging from $0.04 \%$ to $6.7 \%$. ${ }^{[9]}$ Deferral rates may vary according to clinical expertise and also clinical setting and type of specimen encountered. ${ }^{[10]}$ In our study, deferral cases were from ovary and submandibular gland.

Frozen section is a multistep process involving surgical resection, intraoperative preparation of slides and their microscopic examination, communicating FS diagnosis to surgeon and processing the remaining tissue for further workup. Errors may occur due to problems in any of the steps. ${ }^{[8]}$ Several factors can affect the accuracy of FS diagnosis, including sampling error, technical error and interpretation error. Interpretation errors resulting from technical artefacts like freezing procedure or sectioning can be overcome by experience of the pathologist. ${ }^{[1]}$ In our study, two cases from ileocecal mass and from nasal cavity mass were diagnosed as Inflammatory lesions on FS turned out to be NHL on PS. Small biopsy as well as microscopically cellular outline and nuclear details were also not well delineated especially in inflamed, edematous and fatty tissues, while they were well preserved in solid tissues. Due to this, the overall morphology and histological quality of FS was inferior when compared to routine section. An important technical factor causing difficulty in interpretation is quality of section which limits the evaluation of cellular details. This factor is emphasized in most available studies. ${ }^{[12,13]}$ In the present study, we observed that most frequent limitations observed were technical errors followed by sampling errors. Sampling error was the main reason for the diagnostic discrepancy in the current study. The same was reported in previous study by Mohammad et al. ${ }^{[13]}$ However, use of frozen section with limitations in mind make it a highly sensitive and specific technique playing critical role in management of patients. ${ }^{[14]}$

In spite of these disadvantages, overall diagnostic accuracy of FS in ovary was reported to be reliable in large series ranging from $84.25 \%$ to $97.1 \%{ }^{[15-21]}$ which was $87.50 \%$ in our study. Three patients were diagnosed false negative in our study. Diagnostic discrepancy was greater in cases of serous tumors with a borderline diagnosis on frozen section. KK Shih et al. in their study noted that if micropapillary features are present on frozen section analysis, there is greater chance of reclassification on final histopathology. ${ }^{[22,23]}$ In our study, one case was of Papillary Serous cyst Adenoma turned out to be serous carcinoma with micropapillary features. ${ }^{[22]}$ The possible reasons for discordance between FS and PS in BL mucinous tumors are associated with characteristics of these tumors, such as larger sizes, and presence of benign, BL and malignant components in the same tumor, in contrast to serous tumors. ${ }^{[15]}$ The samples should be taken from the thickest and solid areas of the cystic neoplasms. Two patients were upgraded from BL to malignant. One case, that was diagnosed BL papillary serous neoplasm on FS turned out to be Serous cyst adenocarcinoma on PS and other case, that was diagnosed BL epithelial tumor turned out to be Mucinous cystadeno-carcinoma on PS. In our study, we inform the surgeons to be cautious about the possibility of invasion focus in PS samples in BL mucinous tumors. In these situations, we prefer to report as "At least BL mucinous tumor" which was also recommended by Shih et al. ${ }^{[23]}$ Ovarian BL tumors, especially mucinous types are the most stressful neoplasms in FS. ${ }^{[15]}$ Borderline ovarian tumors were a major cause of diagnostic discrepancy in this study. Although there are well defined criteria for the diagnosis of borderline tumors, the diagnosis by frozen section examination is relatively difficult. ${ }^{[22]}$

In major published studies of consecutive FS examinations reported in the literature, the breast is always listed as an organ most frequently examined. ${ }^{[24]}$ Out of 117 cases in 
the present study, 29 cases $(98.3 \%)$ were of breast with an accuracy rate of $89.66 \%$. Intraoperative consultation was requested for primary diagnosis of tumour as malignant, assessment of margins of tumour excision and assessment of lymph node involvement; to decide the extent of surgical excision. In our study, one case was diagnosed false positive. Mammary duct ectasia was misdiagnosed as invasive ductal carcinoma. Under the microscope, there were dilatation of large lactiferous ducts, with accumulation of fatty debris in lumen and fibrous thickening of wall, which contained an increased amount of elastic fibers. The ductal cells showed atypia on frozen section. Calcification is a common finding in mammogram. Clinically it mimics malignancy. ${ }^{[25]}$ Sometimes inconsistencies are presented when clinical symptoms and microscopic findings are compared, for example, in granulomatous mastitis, [26-29] fat necrosis and mammary duct ectasia, clinical symptoms might also be misinterpreted as breast carcinoma. There was a difference in opinions (or disagreements of the views) between the surgeon and pathologist at that moment. The lesion seemed to be benign on gross finding to the surgeon during operation.

Second, the circumstances that frequently lead to false negative diagnosis should be discussed. In our study two cases of FN were diagnosed. One case was diagnosed Inflammatory lesion and another was diagnosed lobular hyperplasia with atypical cells in FS turned out to be invasive ductal carcinoma on PS . The well-differentiated papillary carcinoma, diffused pattern of invasive lobular carcinoma and tubular carcinoma were frequently misdiagnosed as benign lesions. Of course, the morphology of these lesions was similar to that of some benign lesions. Moreover, the pathologists have knowledge from most of published reports that the benign lesions were sometimes confused with mentioned carcinoma. So, they would rather choose a low-diagnosis for these lesions than a high-diagnosis. ${ }^{26]}$

In Skin cases; one case was of ulcer over foot; which was diagnosed as Squamous cell carcinoma with margins and base free from tumour. Another case was ulcer over back; this was also squamous cell carcinoma. But the base showed presence of tumour cells on frozen section. Repeat tissue was requested from surgeon, which showed base free from tumour cells. All skin cases were concordant in frozen and paraffin sections.

GI cases were mostly from Colon specimens. The reason for GI cases was to know about the tumour being malignant and to assess the margins free of tumour. Endoscopic biopsies were not done prior to Frozen section.

In the hands of trained and experienced pathologists, frozen section is one of the most accurate diagnostic procedures currently available, and its reliability and high degree of accuracy in palpable breast lesions is well established. If surgery is performed in close cooperation with a pathologist, the interpretation of frozen section allows a definite one stage surgical procedure possibly leading to a reduction in medical costs. ${ }^{[2]}$ In short, intra-operative frozen section diagnosis of breast lesion is particularly important. It is still a dominant and effective examination at present, even though there are certain shortcomings.

\section{Conclusions}

The accuracy of frozen section diagnosis at our institute can be interpreted as comparable with most international quality control statistics for frozen sections. The overall discordance rate and deferral rates are within the range of previously published studies. Methodological gross/macroscopic examination, accurate sampling by pathologist, avoiding technical errors in sectioning and staining, and communication with the operating surgeon can reduce the limitations. Continuous long-term monitoring is emphasized, to recognize the reasons of discordance and, if possible, to reduce them.

\section{Acknowledgement}

We acknowledge the precious help of our Head of Department; the communication from surgical clinicians; and last but not the least, our histopathology technical staff.

\section{Conflict of Interests}

None declared

\section{References}

1. Raab SS, Tworek JA, Souers R, Zarbo RJ. The value of monitoring frozen section-permanent section correlation data over time. Archives of pathology \& laboratory medicine. 2006 Mar;130(3):337-42.

2. Khoo JJ. An audit of intraoperative frozen section in Johor. The Medical journal of Malaysia. 2004 Mar 1;59(1):50-5.

3. Jerome BT. Frozen section and surgical pathologist. ArchPathol Lab Med 2009; 133:1135-1138.

4. Patil P, Shukla S, Bhake A, Hiwale K. Accuracy of frozen section analysis in correlation with surgical pathology diagnosis. Int J Res Med Sci. 2015 Feb;3(2):399-404.

5. Raab SS, Tworek JA, Souers R, Zarbo RJ. The value of monitoring frozen section-permanent section correlation data over time. Archives of pathology \& laboratory medicine. 2006 Mar;130(3):337-42.

6. Mahe E, Ara S, Bishara M, Kurian A, Tauqir S, Ursani N, Vasudev P, Aziz T, Ross C, Lytwyn A. Intraoperative pathology consultation: error, cause and impact. Canadian Journal of Surgery. 2013 Jun;56(3):E13.

7. Hatami H, Mohsenifar Z, Alavi SN. The diagnostic accuracy of frozen section compared to permanent section: 
a single center study in Iran. Iranian journal of pathology. 2015;10(4):295.

8. Shah HS, Daveshwar MR, Rana NA. Correlation of intraoperative frozen section report and histopathological diagnosis. MedPulse International Journal of Pathology. 2019 12(3),

9. Chbani L, Mohamed S, Harmouch T, El Fatemi H, Amarti A. Quality assessment of intraoperative frozen sections: An analysis of 261 consecutive cases in a resource limited area: Morocco. Health. 2012 Jul 19;4(7):433-5.

10. Gephardt GN, Zarbo RJ. Interinstitutional comparison of frozen section consultations: a College of American Pathologists Q-Probes study of 90538 cases in 461 institutions. Archives of pathology \& laboratory medicine. 1996 Sep 1;120(9):804.

11. Chandramouleeswari K, Yogambal M, Arunalatha P, Bose JC, Rajendran A. Frozen and paraffin sections-Comparative study highlighting the concordance and discordance rates in a tertiary care centre. IOSR Journal of Dental and Medical Sciences. 2013 Nov;12(5):26-30.

12. Abdelghany AM, Arafa EM, Madkour NM, Nossair WS, Mohamed EA, Abdelsalam WA, Salem AA. Accuracy of intraoperative frozen section in the diagnosis of ovarian neoplasms. Open Journal of Obstetrics and Gynecology. 2014 Dec 25;5(01):14.

13. Mohammed AB, Ahuja VK, Farghaly H. Role of frozen section in the intraoperative management of ovarian masses. Middle East Fertility Society Journal. 2015 Jun 1;20(2):97-101.

14. Mayun AA, Pindiga UH, Abubakar A. Frozen Section: The need [12] for intra-operative consultation between the surgeon and the pathologist. BOMJ. 2006;3(2):1-2.

15. Açikalin A, Torun G, Bağir E, Bayram F, Zeren H, Güleç $\mathrm{U}$, Güzel AB, Gümürdülü D. Intraoperative frozen section in ovarian neoplasms; a tertiary center experience. Turk Patoloji Derg. 2014 Jan 1;30(3):184-8.

16. Bige O, Demir A, Saygili U, Gode F, Uslu T, Koyuncuoglu M. Frozen section diagnoses of 578 ovarian tumors made by pathologists with and without expertise on gynecologic pathology. Gynecologic oncology. 2011 Oct 1;123(1):43-6.

17. Yarandi F, Eftekhar Z, IZADI-MOOD N, Shojaei H. Accuracy of intraoperative frozen section in the diagnosis of ovarian tumors. Australian and New Zealand Journal of Obstetrics and Gynaecology. 2008 Aug;48(4):438-41.

18. Rakhshan A, Zham H, Kazempour M. Accuracy of frozen section diagnosis in ovarian masses: experience at a tertiary oncology center. Archives of gynecology and obstetrics. 2009 Aug;280(2):223-8.

19. Subbian A, Devi UK, Bafna UD. Accuracy rate of frozen section studies in ovarian cancers: A regional cancer institute experience. Indian journal of cancer. 2013 Oct 1;50(4):302.

20. Toneva F, Wright H, Razvi K. Accuracy of frozen section in the diagnosis of ovarian tumours. Journal of Obstetrics and Gynaecology. 2012 Jul 1;32(5):479-82.

21. Ilvan S, Ramazanoglu R, Akyildiz EU, Calay Z, Bese T, Oruc N. The accuracy of frozen section (intraoperative consultation) in the diagnosis of ovarian masses. Gynecologic oncology. 2005 May 1;97(2):395-9.

22. Sukumaran R, Somanathan T, Mathews A, Kattor J, Sambasivan S, Nair RP. Role of frozen section in intraoperative assessment of ovarian masses: a tertiary oncology center experience. Indian journal of surgical oncology. 2014 Jun;5(2):99-103.

23. Shih KK, Garg K, Soslow RA, Chi DS, Abu-Rustum NR, Barakat RR. Accuracy of frozen section diagnosis of ovarian borderline tumor. Gynecologic oncology. 2011 Dec 1;123(3):517-21.

24. Kayani N, Sultana N. Validity of frozen section in the diagnosis of breast lumps: 5 years experience at the Aga Khan University Hospital. Journal of Pakistan Medical Association. 2005;55(12):533.

25. Rosai, J., Ackerman, L. V. (2004). Rosai and Ackerman's Surgical Pathology. Malawi: Mosby.

26. Yun N, Fu XL, Yong Y, Wang PP, Cao XC. Intra-operative frozen section diagnosis of breast lesions: a retrospective analysis of 13243 Chinese patients. Chinese medical journal. 2007 Apr 1;120(8):630-5.

27. Sakurai T, Oura S, Tanino H, Yoshimasu T, Kokawa Y, Kinoshita T, Okamura Y. A case of granulomatous mastitis mimicking breast carcinoma. Breast cancer. 2002 Jul $1 ; 9(3): 265-8$.

28. Asoglu O, Ozmen V, Karanlik H, Tunaci M, Cabioglu N, Igci A, Selcuk UE, Kecer M. Feasibility of surgical management in patients with granulomatous mastitis. The breast journal. 2005 Mar;11(2):108-14.

29. Chaney AW, PollackA, Mcneese MD, Zagars GK, Pisters PW, Pollock RE, Hunt KK. Primary treatment of cystosarcoma phyllodes of the breast. Cancer: Interdisciplinary International Journal of the American Cancer Society. 2000 Oct 1;89(7):1502-11.

*Corresponding author:

Dr. Falguni Goswami, B-7 Kailash Park Society, Behind Reliance Mega Mall. Old Padra Road. Vadodara, Gujarat. India. PINCode: 390020

Phone: +91 9924344184

Email: falgunig2502@gmail.com

Date of Submission $\quad: 21 / 09 / 2020$

Date of Final Revision : 30/01/2021

Financial or other Competing Interests: None.

Date of Acceptance $\quad: 04 / 02 / 2021$

Date of Publication : 28/02/2021 